\title{
The length-tension diagrams of human oblique muscles in trochlear palsy and strabismus sursoadductorius
}

\author{
H.J. SIMONSZ, G.H. KOLLING, H. KAUFMANN \& B. VAN DIJK \\ From the Augenklinik für Schielbehandlung und Neuroophthalmologie, Giessen, BRD, and \\ the Netherlands Ophthalmic Research Institute, P.B. 12141, NL 1100 AC, Amsterdam, the \\ Netherlands
}

Accepted 30 August 1988

Key words: eye movements, eye muscles, length-tension curves, eye muscle palsy

\begin{abstract}
We determined the relation between length and tension in detached oblique muscles of 16 strabismus patients that underwent surgery, before and during contraction evoked by intravenous administration of succinylcholine. We frequently found a nonlinear relation between length and tension, unlike our previous findings in recti. In superior oblique palsies, the superior oblique was found, before injection of succinylcholine, to be stiff after elongation, and did not contract after injection of succinylcholine, while the ipsilateral inferior oblique contract after injection of succinylcholine, but with a higher spring constant than did usual. In 3 cases the superior oblique contracted vividly after administration of succinylcholine despite the presence of excyclotropia, stereopsis, torticollis ( 2 cases) and a hypertropia that increased in adduction, in downgaze, in adduction-and-downgaze and on ipsilateral head-tilt. The finding of a vividly contracting superior oblique is incompatible with the diagnosis of a complete superior oblique palsy. We conclude that some of the cases diagnosed as congenital superior oblique palsy, having a hypertropia increasing in adduction, in downgaze, in adduction-anddowngaze and on ipsilateral head-tilt, are in fact cases of unilateral strabismus sursoadductorius (upshoot in adduction), a non-paretic motility disorder.

This work was supported by a fellowship of the Royal Netherlands Academy of Arts and Sciences (Dr Simonsz).
\end{abstract}

\section{Introduction}

We have made intraoperative continuous-registration length-tension diagrams of detached oblique muscles in 16 patients under general anaesthesia, repeated after contraction evoked by succinylcholine chloride. The tension in a contracting muscle is caused by (1) the tension generated actively by the sarcomeres and (2) the tension resulting from passive stretch of the connec-

This work was supported by a fellowship of the Royal Netherlands Academy of Arts and Sciences (Dr Simonsz). 
tive tissue of the muscle. The relation between the latter and muscle length is exponential [1]. In other words, the tension is zero at lengths shorter than a certain length (in rabbits, this length is approximately equal to the primary-position length [2]), increases slowly when the muscle is stretched from primary-position length onwards, to increase ever more rapidly thereafter, until the muscle tears. The tension generated actively by the sarcomeres, at a given level of innervational stimulation, is low when the muscle is short, is highest approximately at average in-situ length (or slightly more than that), and declines again when the muscle is stretched further. The reason that the maximum-tension development occurs at this particular length is that at approximately this length the intertwining actine and myosine molecules are engaged over a distance that permits the largest possible number of actine-myosine cross-bridges to contract unencumbered [3].

It has been found previously that the relation between length and tension of a contracting eye muscle is linear at higher levels of stimulation $[1,4,5]$. In other words, a contracting eye muscle behaves like an ordinary coil spring, in that the tension rises proportionately to the length. What mechanism is responsible for this linear relation between length and tension? How can the relation between length and tension of a contracting eye muscle be linear when both of its components, i.e. tension generated by the sarcomeres (active component) and tension resulting from stretch of the connective tissue (passive component) are nonlinear? When a contracting, short muscle is stretched, at first the tension generated by the sarcomeres rise proportionately to the length. As the muscle is stretched further and the tension generated by the sarcomeres decreases, the tension resulting from stretch of the connective tissue, however, increases so much more, that the overall tension still increases proportionately to the length. Clearly, whether or not the relation will be linear depends upon the amount of connective tissue in the muscle and the structure of the muscle. Some skeletal muscles, like the sartorius muscle, have little connective tissue and the active component predominates in the length-tension curve. Hence, their relation between length and tension is nonlinear. A gastrocnemius muscle, on the other hand, has much connective tissue and its relation between length and tension is almost linear [6]. Eye muscles also have much connective tissue [2] and, hence, the length-tension relation of a contracting eye muscle is almost linear. Only at low levels of innervation or stimulation does the length-tension curve become nonlinear, as the exponential length-tension relation of the connective tissue of the muscle predominates. It has also been found that the spring constant ( $=$ stiffness) of a contracting eye muscle remains approximately the same whether it contracts moderately or strongly $[1,4,5]$.

In the experiments that are the subject of this study, we let the eye 
muscles contract by intravenous administration of succinylcholine chloride while registering length and tension. Acetylcholine and succinylcholine chloride cause contraction of extraocular muscles [2, 7, 8, 9] by preferentially stimulating multiply innervated muscle fibers. These fibers have acetylcholine receptors not only in the neuromuscular junction, but on their entire cell membrane [2].

In short, we found nonlinear length-tension relations frequently in oblique muscles. Surprisingly, three cases that could have been diagnosed as superior oblique palsies had vividly contracting superior oblique muscles.

\section{Methods}

The measurement procedure has been described elsewhere [1]. During surgery a length and tension measuring device [10] was fixed rigidly above the head of the patient. It consisted of a $2 \mathrm{~mm}$ hardened steel shaft, suspended by precision microballbearings and equipped with a shaft-position encoder and an eddy-current motor. The torque generated by the eddy-current motor in the shaft and the position of the shaft could be assessed electronically. The frame on which it was mounted consisted of $30 \mathrm{~mm}$ steel posts fixed to the railing of the operating table, a $20 \mathrm{~mm}$ steel traverse bar above the chest of the patient and a $20 \mathrm{~mm}$ steel bar that could be clamped tight in any position perpendicular to the traverse bar. The head of the patient was fixed rigidly on the circular cushion of the steel head-support by a wide silk plaster around the patient's forehead and the head-support. A 4.0 silk suture was passed through one of the muscles to be measured and wrapped around the shaft with a tight knot. When measuring oblique muscles, the head of the patient was rotated contralaterally and the measuring device was positioned such that the muscle was pulled upon in a frontal plane. The torque generated in the shaft was slowly (taking more than $45 \mathrm{~s}$ each way) increased and decreased, exerting a pull that varied between 0 and $40 \mathrm{~g}$. We repeated the measurements after intravenous injection of succinylcholine chloride (a short-acting muscle relaxant), $1 \mathrm{mg} / \mathrm{kg}$ body weight, starting the first registration 1 minute after the injection. Calibration of the length-tension measuring device was as described previously [1]. The starting friction of the shaft, due to the precision microballbearings, was less than 1 gram.mm. All patients gave written informed consent.

\section{Results}

The patient data and the spring constants of the contracting eye muscles, 
Table 1. Patients: age, diagnosis, angles of squint and spring constants.

1. 19y Decompensated sursoadd, V; far: 0 deg, on up/down gaze: $-7 /+4 \mathrm{deg}$, near: $-7 \mathrm{deg}$; VD: $+7 \mathrm{deg}$, on right/left gaze: $+5 /+13 \mathrm{deg}$, on left + up/ down gaze: $+10 /+12$ deg Bielschowsky: $+10 /+5 \mathrm{deg}$; excyclo; $4 \mathrm{deg}$; stereopsis: $20^{\prime \prime} 10 \mathrm{mg} \mathrm{ALC}$

RSO \& RIO both nonlin

2. 3y Decompensated esoph, V, sursoadd; far: $+10 \mathrm{deg}$, on up/down gaze: $+5 /+20 \mathrm{deg}$, near: $+15 \mathrm{deg}$; VD: $+2 \mathrm{deg}$, on right/left gaze: $-10 /$

+17 deg, Bielschowsky: $+6 /+6$ deg; stereopsis: TNO and Titmus Fly positive; $1 \mathrm{mg} \mathrm{VEC}$

RIO .37, LIO .37, RIO little contraction

3. 35y Left superior oblique palsy; torticollis; VD: $-2 \mathrm{deg}$, on right/left gaze:

$-8 / 10 \mathrm{deg}$, on right + up/down gaze: $-4 /-14 \mathrm{deg}$, Bielschowsky: -2 /

-6 deg; excyclo: +2 deg; stereopsis: $+20^{\prime \prime} ; 8 \mathrm{mg} \mathrm{VEC}$

LSO nct, LIO 1.18

4. 37y Left superior oblique palsy; torticollis; VD: $-5 \mathrm{deg}$, on right/left gaze:

$-12 /-1 \mathrm{deg}$, on right + up/down gaze: $-14 /-11 \mathrm{deg}$, Bielschowsky: $0 /$

- 10 deg; excyclo: +3 deg; stereopsis: $+20^{\prime \prime}$

LSO nct, LIO .43

5. 6y Conv, V, sursoadd, far: $+12 \mathrm{deg}$, near $+12 \mathrm{deg}$, on up/down gaze: $+6 /$

$+16 \mathrm{deg}$; VD: $-3 \mathrm{deg}$, on right/left gaze: $-15 /+4 \mathrm{deg}$, Bielschowsky:

not measured; no binocular vision; $0.5 \mathrm{mg}$ VEC

RIO .34, LIO .34, partly nonlin

6. 10y Left microstrabismus, anisometropia with left hypermetropia, torticollis; far: $+3 \mathrm{deg}$, nesar $+2 \mathrm{deg}$; VD: $-10 \mathrm{deg}$, on right/left gaze; $-15 /-2 \mathrm{deg}$, on right $+\mathrm{up} /$ down gaze: $-10 /-19 \mathrm{deg}$, Bielschowsky: $-2 /-9 \mathrm{deg}$; excy-

clo: $+5 \mathrm{deg}$; stereopsis: $140^{\prime \prime}, 2 \mathrm{mg} \mathrm{ALC}$

LSO .49, LIO .43, SO more contraction than IO

7. 6y Conv, sursoadd, V, DVD; far: +10 to $+17 \mathrm{deg}$, on up/down gaze: $+9 /$ $+20 \mathrm{deg}$, near: +17 to $+20 \mathrm{deg} ; 1 \mathrm{mg} \mathrm{VEC}$

RIO and LIO nonlin, both little contraction

8. 21y Left superior oblique palsy; torticollis; VD: $0 \mathrm{deg}$, on right/left gaze: $-7 /$ $-1 \mathrm{deg}$, on right + up/down gaze: $-9 /-8 \mathrm{deg}$, Bielschowsky: $+1 /-7 \mathrm{deg}$; excyclo: +2 deg; stereopsis: 70"; 4 mg VEC

LSO nct

9. 6y Conv, sursoadd, V, right amblyopia (0.6); far: $+32 \mathrm{deg}$, on up/down gaze: $+25 /+35 \mathrm{deg}$, near: $+32 \mathrm{deg}$; VD: $+5 \mathrm{deg}$, on right/left gaze: $-3 /$

+8 deg Bielschowsky: not measured

RIO and LIO nonlin, both modest contraction

10. 7y Conv, sursoadd, V, DVD, right amblyopia; far: +17 , on up/down gaze: $+9 /+21 \mathrm{deg}$; VD: dissociated, on right/left gaze: $-12 /+6 \mathrm{deg}$ but with dark red before fixing eye $-4 / 0 \mathrm{deg} ; 0.5 \mathrm{mg}$ VEC

RIO and LIO nonlin, both modest contraction

11. 24y Right superior oblique palsy; torticollis; far: -5 , on right/left gaze: $-1 /$

$-8 \mathrm{deg}$; VD: $+9 \mathrm{deg}$, on right/left gaze: $+1 /+18 \mathrm{deg}$, on up/down gaze: $+7 /+8 \mathrm{deg}$, on left + up/down gaze: $+15 /+21 \mathrm{deg}$, Bielschowsky: $+15 /+2$ deg; excyclo: +5 deg; stereopsis: $400^{\prime \prime} ; 6 \mathrm{mg}$ VEC

RSO nct, RIO little contraction

12. 35y Left superior oblique palsy after removal of eyelid tumor 1 year previously; torticollis; VD: $-7 \mathrm{deg}$, on right/left gaze: $-10 /-3 \mathrm{deg}$, on 
Table 1. Continued

right + up/down gaze: $-3 /-15 \mathrm{deg}$, Bielschowsky: $-5 /-10 \mathrm{deg}$; excyclo:

$7 \mathrm{deg}$; stereopsis: $20^{\prime \prime} ; 5 \mathrm{mg}$ VEC

LSO nct, LIO 0.44, LIO modest contraction

13. 3y Left superior oblique palsy, torticollis; far: $-7 \mathrm{deg}$, near: $+1 \mathrm{deg}$; VD:

$-12 \mathrm{deg}$, on right/left gaze: $-15 /+1 \mathrm{deg}$, on up/down gaze: $-8 /-17 \mathrm{deg}$,

on right + up/down gaze: $-13 /-18 \mathrm{deg}$, Bielschowsky: $-4 /-17 \mathrm{deg}$; binocular vision: Bagolini positive; $0.5 \mathrm{mg}$ VEC

LSO nct, LIO .55, LIO little contraction

14. 2ly Left superior oblique palsy; torticollis; VD: $-6 \mathrm{deg}$, on right/left gaze:

$-16 /-2 \mathrm{deg}$, on right + up/down gaze: $-10 /-20 \mathrm{deg}$, Bielschowsky: $-3 /$

- 19; excyclo: + 2 deg; stereopsis: 20 "; 2 mg VEC

LSO .35 , LIO .48 , LSO partly nonlin, both modest contraction

15. 15y SUrsoadd, no torticollis; far $-3 \mathrm{deg}$, near $-7 \mathrm{deg}$; VD: $+2 \mathrm{deg}$, on right/left gaze: $0 /+4$ deg, on up/down gaze: $+2 /+2$ deg, Bielschowsky: $+5 /+1 \mathrm{deg}$; excyclo: $+11 \mathrm{deg}$; stereopsis: $50^{\prime \prime} ; 6 \mathrm{mg}$ VEC

RSO and LSO nonlin, strong contraction

16. 18y Conv, V, sursoadd, myopia; far: $40 \mathrm{deg}$, on up/down gaze: $30 / 48 \mathrm{deg}$, near: $+46 \mathrm{deg}$; VD: $-2 \mathrm{deg}$, on right/left gaze: $-2 /+5 \mathrm{deg}$, Bielschowsky: $-1 /+5 \mathrm{deg}$; excyclotropia: $12 \mathrm{deg} ; 6 \mathrm{mg}$ VEC

RSO nct, RIO .48, RIO modest contraction

Table of essential patient data and spring constants of contracting eye muscles found during succinylcholine-chloride induced contraction. The spring constants are, for convenience, expressed in unit gram per degree of eye rotation, assuming a radius of the globe of $11.7 \mathrm{~mm}$, conforming to $24.6 \mathrm{~mm}$ axial length. Then 1 degree on the surface of the globe equals $0.2042 \mathrm{~mm}$. These constants are preceded by the essential patient data: case number, age, diagnosis and angle of squint. V denotes V-pattern; A, A-pattern; VD, vertical divergence (negative operation sign indicates left hypertropia); DVD, dissociated vertical divergence; rec, recess surgery; res, resect surgery; Bielschowsky, VD's in Bielschowsky head-tilt test, on head tilt to the right and left shoulder, respectively; sursoadd, strabismus sursoadductorius (elevation in adduction); deorsadd, strabismus deorsadductorius (depression in adduction); far, angle of squint at far, using alternating cover test; near, angle of squint at near, using alternating cover test. ALC denotes alcuronium chloride and VEC, vecuronium bromide. These are both nondepolarizing muscle relaxants and were given at intubation, 25 to 50 minutes before the first measurement. When no mention is made of 'ALC' or 'VEC', no data were available on the administration of nondepolarizing muscle relaxants during intubation. $S O$ and IO refer to the eye muscles, preceeded by ' $R$ ' or ' $L$ ' for right or left eye, respectively; 'nct' denotes no contraction on injection of succinylcholine chloride, 'nonlin', denotes a nonlinear length-tension curve after contraction evoked by succinylcholine chloride.

which are equal to the slope of the length-tension curves, are listed in Table 1. The spring constants are, for convenience, expressed in unit gram per degree of eye rotation, assuming a radius of the globe of $11.7 \mathrm{~mm}$, conforming to $24.6 \mathrm{~mm}$ axial length. Then 1 degree on the surface of the globe equals $0.2042 \mathrm{~mm}$.

All patients were diagnosed as either strabismus sursoadductorius (upshoot in adduction) or trochlear palsy. In those cases where both oblique 


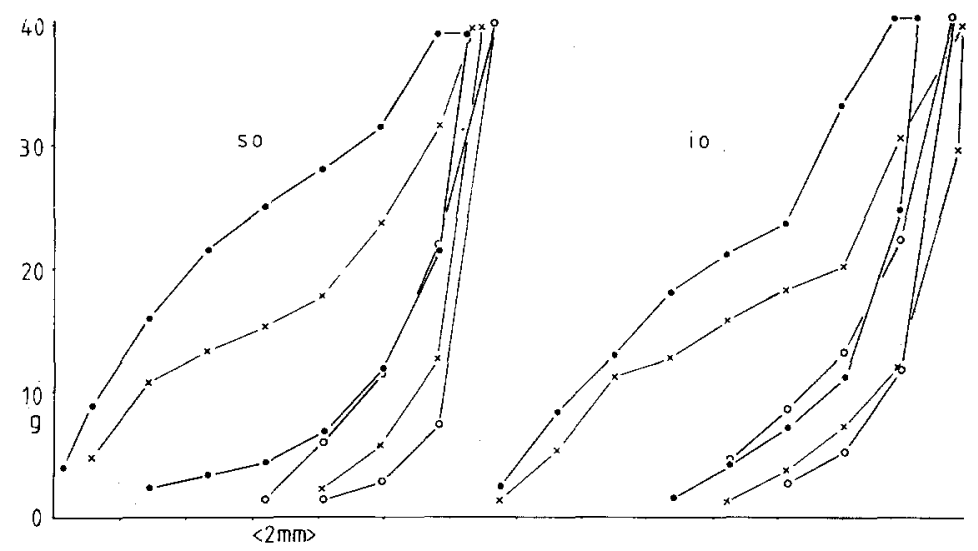

Fig. 1. Length-tension diagrams of superior (SO) and inferior oblique (IO) muscles, case 1. In Figs. 1-3, the traces of two muscles are set side by side for comparison. All length-tension diagrams were composed of a left limb (registration during tension increase) and a right limb (registration during tension decrease). The difference between the two limbs was caused by hysteresis, mainly friction of the muscle in its sheaths. Open circles: before injection of succinylcholine chloride, $1 \mathrm{mg} / \mathrm{kg}$ of body weight; solid circles: registration starting one minute after injection; crosses; registration starting approximately four minutes after injection. In the first measurement after injection of succinylcholine chloride, seemingly larger hysteresis is caused by diminishing action of succinylcholine chloride. Note nonlinearity.

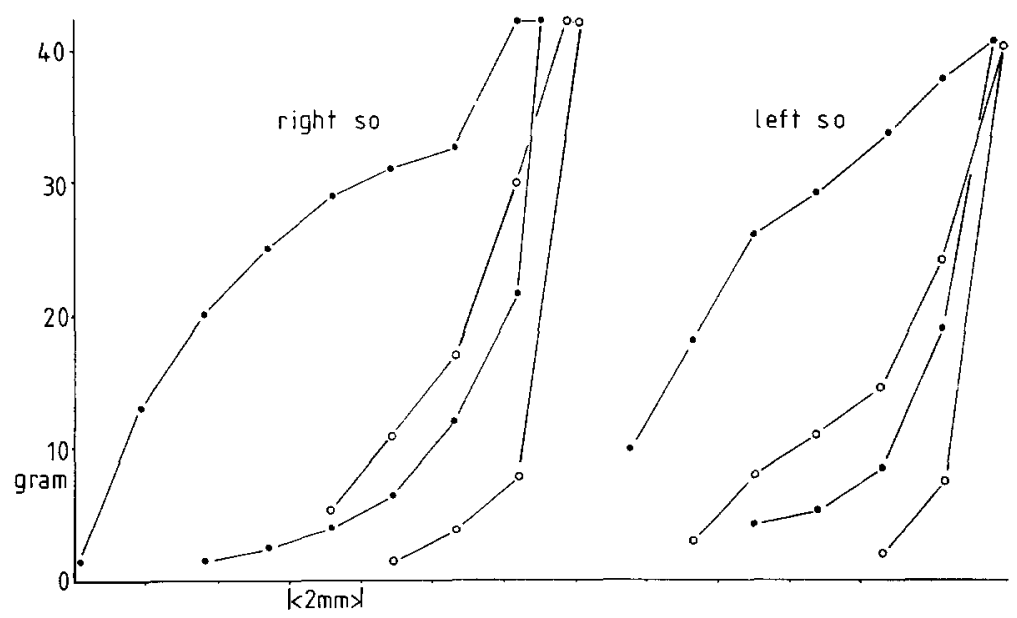

Fig. 2. Right and left superior oblique muscles of case 15 . Note nonlinearity. Cases 1 (Fig. 1) and 15 both had hypertropia increasing in adduction, in down-gaze, in adduction and down-gave and on ipsilateral head-tilt. The superior oblique muscles contracted vividly however, after stimulation with succinylcholine chloride. Probably these patients did not have superior oblique palsy but monolateral strabismus sursoadductorius. 
muscles contracted vividly and equally (not compatible with a superior oblique palsy), the relation between length and tension was frequently nonlinear (Figs. 1, 2). In some cases (10, 13 and 14), neither oblique muscle contracted much on injection of succinylcholine chloride. The stiffness of the oblique muscles (often a rough estimate as the curves were frequently nonlinear) was comparable to that of recti muscles. Vividly and equally (i.e. similar length-tension curves for inferior and superior obliques) contracting oblique muscles were mainly found in young patients, the oldest patients being 10 and 19 years old. In other cases the superior oblique muscle was found to be stiff (after elongation) and did not contract after injection of succinylcholine chloride, compatible with a diagnosis of trochlear palsy (Fig. 3). In these cases, the ipsilateral inferior oblique muscle did contract on injection of succinylcholine chloride, but with a higher spring constant than usual, compatible with a contracture of the ipsilateral antagonist. The latter picture was seen more frequently in older patients.

\section{Discussion}

In oblique muscles, the relation between length and tension was frequently nonlinear, even when both oblique muscles contracted vividly. Whether this is due to pathological changes in these muscles, to their connective

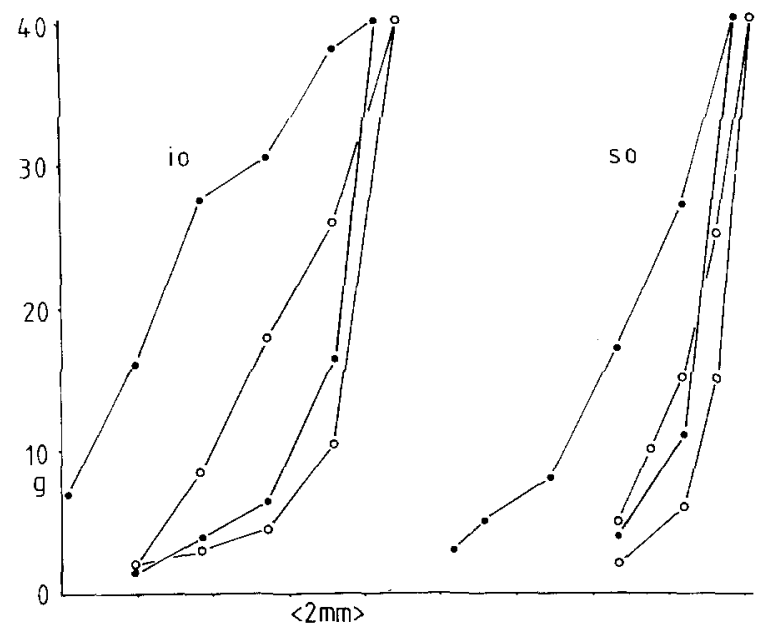

Fig. 3. Superior and inferior oblique muscles of case 3: superior oblique palsy. Note absence of contraction of the superior oblique muscle after administration of succinylcholine chloride on account of palsy, and increased stiffness of the inferior muscle, i.e. contracture of the ipsilateral antagonist. 
tissue being quantitatively or qualitatively different, or whether these findings are related to their smaller change in length in vivo as compared to recti muscles [11], is unclear at present. In some cases (10,13 and 14), neither oblique muscle contracted much on injection of succinylcholine chloride, possibly because the muscles were still under the influence of the alcuronium chloride or vecuronium bromide given at intubation. All measurements were performed, however, at least 25 minutes after administration of either muscle relaxant. Moreover, this lack of contraction was never seen in recti muscles. The spring constants of oblique muscles (often rough estimates as the curves were frequently nonlinear) were comparable to those of recti muscles. This is amazing because the oblique muscles are much thinner than rectus muscles.

In superior oblique palsies, the superior oblique muscles was found to be stiff after elongation, before injection of succinylcholine chloride, and did not contract after injection of succinylcholine chloride (Fig. 3). In these cases the ipsilateral inferior oblique did contract after injection of succinylcholine chloride but with a higher spring constant than usual (i.e. contracture of the ipsilateral antagonist).

The results of all measurements of oblique muscles were fully compatible with the clinical findings except in cases 1, 6 and 15 (19, 10 and 15 years old, respectively). In these three cases the superior oblique muscle contracted vividly after administration of succinylcholine chloride despite the presence of a vertical divergence that increased in adduction, in downgaze, in adduction-and-downgaze and on ipsilateral head-tilt (Bielschowsky's head-tilt test) (Figs. 1, 2). These patients had excyclotropia, stereopsis and torticollis ( 2 cases). The finding of a vividly contacting superior oblique muscle is incompatible with the diagnosis of a complete superior oblique palsy. In our opinion, some cases of congenital superior palsy that are diagnosed using the criteria mentioned above, may in fact be unilateral strabismus sursoadductorius (upshoot in adduction). The fact, however, that the Bielschowsky head-tilt test can be positive in this motility disorder, implies that real under- or overactions must be present in these cases. The increase in vertical divergence from adduction-upgaze to adductiondowngaze seemed a reliable parameter for a superior oblique palsy. Similarly, it has been emphasized that a superior oblique palsy is more likely if the differences between the vertical divergences in Bielschowsky's head-tilt test are larger when the test is performed in downgaze than in up-gaze [12].

Viirre, Cadera and Vilis [13], have found that, after patching the eye of a macaque-monkey for a week, strabismus sursoadductorius appears (the other eye performing either horizontal saccades or vestibular eye movements). They suggest that, when binocular vision is present, the direction of 
horizontal eye movements is calibvrated continuously in the pons by fusion. We suggest that strabismus surso- and deorsoadductorius in humans may be caused by malfunctioning of this calibration. We propose that a distinction be made between primary and secondary strabismus surso- or deorsoadductorius. Secondary strabismus surso- or deorsoadductorius is a latent motility disorder that becomes manifest after disruption of binocular vision, by a horizontal squint in childhood, for instance. The clinical observation that strabismus surso- or deorsoadductorius usually appears later than, not simultaneously with, a horizontal squint is compatible with this model. The disappearance of strabismus sursoadductorius after correction of horizontal strabismus [14] is also compatible with this model. In primary strabismus surso- or deorsoadductorius the latent motility disorder, i.e. the latent strabismus sursoadductorius, becomes too large to be handled by the calibration mechanism. According to this model, there should be patients presenting with a decompensated vertical divergence that increases in adduction, in downgaze and on head-tilt, with excyclotropia and a long-standing torticollis, but without a history of trauma. In three of our cases that could have been diagnosed as congenital superior oblique palsies, we found superior oblique muscles that contracted vividly on intravenous administration of succinylcholine, thus, excluding a superior oblique palsy in these cases. We suggest that these patients had in fact primary strabismus sursoadductorius.

\section{References}

1. Simonsz HJ, Kolling GH, Kaufmann H, van Dijk B. Intraoperative length and tension curves of human eye muscles and stiffness in passive horizontal eye movement in awake volunteers. Arch Ophthalmol 1986; 104:1495-1500.

2. Asmussen G. Morphologische, physiologische und pharmakologische Eigenschaften der äusseren Augenmuskeln und ihre Veränderungen nach Denervation. Dissertation, Leipzig, 1978.

3. Gordon AM, Huxley AF, Julian FJ. The variation in isometric tension with sarcomere length in vertebrate muscle fibres. J Physiol 1966; 184: 170-92.

4. Robinson DA, O'Meara DM, Scott AB, Collins CC. Mechanical components of human eye movements. J Appl Physiol 1969; 26:548-53.

5. Collins CC, Scott AB, O'Meara DM. Elements of the peripheral motor apparatus. Am J Optom 1969; 46:510-15.

6. McMahon TA. Muscles, reflexes and locomotion. Princeton, New Jersey: Princeton University Press, 1984; 8-9.

7. Duke-Elder WS, Duke-Elder PM. The contraction of the extrinsic muscles of the eye by choline and nicotine. Proc Roy Soc B, 1930; 107:332-43.

8. Bach-y-Rita P, Lennerstrand G, Alvarado J, Nichols K, McHolm G. Extraocular muscle fibers: ultrastructural identification of iontophoretically labeled fibers contracting in response to succinylcholine. Invest Ophthalmol Vis Sci 1977; 16:561-65. 
9. Asmussen G, Kiessling A, Wohlrab F. Histochemische Charakterisierung der verschiedenen Muskelfasertypen in den äusseren Augenmuskeln von Säugetieren. Acta Anat 1971; 79:526-45.

10. Simonsz HJ, Crone RA, de Waal BJ, Schooneman M, Lorentz de Haas HAL. Measurement of the mechanical stiffness in cyclotorsion of the human eye. Vision Res 1984; 24:961-68.

11. Clement RA. Description of the length-tension curves of the extraocular muscles. Vision Res 1987; 27:791-92.

12. Kolling GH. Diagnostik und operative Korrektur von Vertikal- und Zyklodeviationen bei Störungen schräger Augenmuskeln. Giessen: Habilitationsschrift, 1986.

13. Viirre E, Cadera $W$, Vilis $T$. The pattern of changes produced in the saccadic system and vestibulo-ocular reflex by visually patching one eye. J Nuerophys 1987; 57:92-103.

14. Bielschowsky A. Disturbances of the vertical motor muscles of the eyes. Arch Ophthalmol 1938; 20:175-200.

Address for offprints: H.J. Simonsz, Netherlands Ophthalmic Research Institute, P.O. Box 12141, 1100 AC Amsterdam, the Netherlands. 